\title{
Oxidation Comparison of Alumina-Forming and Chromia-Forming Commercial Alloys at 1100 and $1200{ }^{\circ} \mathrm{C}$
}

\author{
Bo Jönsson ${ }^{1}$ (iD $\cdot$ Alla Westerlund ${ }^{1}$
}

Received: 19 December 2016/Published online: 10 February 2017

(C) The Author(s) 2017. This article is published with open access at Springerlink.com

\begin{abstract}
Commercial alumina-forming and chromia-forming high-temperature alloys were tested at 1100 and $1200{ }^{\circ} \mathrm{C}$ for up to $1000 \mathrm{~h}$. Exposure was performed in air using 100-h cycles on $\sim 2$-mm-thick test coupons placed in highly sintered alumina crucibles. Visual appearance, gross mass gain and amount of spallation were monitored after every $100 \mathrm{~h}$. Investigation of topography and cross sections was performed in LOM and SEM with EDS at breakaway oxidation or at $1000 \mathrm{~h}$ depending on what occurred first. In order to investigate the earlier part of the oxidation process in more detail, separate samples from all materials were exposed under the same conditions for a single 100-h cycle and were then investigated in the same manor.
\end{abstract}

Keywords Oxidation · Alumina forming · Chromia forming

\section{Introduction}

Application and lifetime of commercial alloys for high-temperature components is mainly controlled by two important properties: oxidation/corrosion behavior and mechanical strength/structural integrity. At high temperatures and at lower

Trademarks: Kanthal APM, Kanthal APMT, Nikrothal, RA330, Inconel, Incoloy, Haynes, Hastelloy, 253MA, 353MA are trademarks held by Sandvik AB, Rolled Alloys Inc., Special Metals Corp., Haynes International, Inc., Avesta Jernverks Aktiebolag and Outukumpu Oyj respectively.

Bo Jönsson

bosse.jonsson@sandvik.com

Alla Westerlund

alla.westerlund@sandvik.com

1 Sandvik Heating Technology, Box 502, 73427 Hallstahammar, Sweden 
mechanical stress levels, the oxidation process becomes the most important lifetime-limiting factor. Such conditions are present in industrial processes such as sintering of powder metallurgical steels and heat treatment of additive manufactured parts and special stainless steels which are performed in the temperature regime above $1100{ }^{\circ} \mathrm{C}$. The properties of the processed components are improved by higher processing temperature, and such conditions are therefore increasingly needed. The process temperatures and design solutions are today at least partially limited by oxidation performance of critical components such as muffles, retorts, furnace rolls and heating elements, and consequently there is a demand for long oxidation life. Material selection and in a longer perspective material and process development are therefore important. The present paper aims to present a broad overview of materials and behaviors among available wrought commercial high-temperature alloys. Two relatively high temperatures were chosen for the exposures: $1100{ }^{\circ} \mathrm{C}$, which is close to the maximum industrially applied temperature for chromia formers and $1200{ }^{\circ} \mathrm{C}$, which is a very high temperature for most chromia formers and medium high temperature for alumina formers. The chosen temperatures represent what materials will experience in, e.g., the external side of muffles and retorts in conventional steel sintering and high-temperature sintering processes.

It is known that there are large differences in oxidation behavior both between different chromia formers depending on, e.g., Ni content and between chromia formers and alumina formers, see, e.g. [1]. It is, however, little available comparative information on commercial alloys, especially in combination with a deeper analysis of the mechanisms that control their behavior [1-3]. In order to highlight high-temperature oxidation behaviors and degradation mechanisms in a wide range of material compositions, 21 wrought commercial high-temperature alloys were studied for up to $1000 \mathrm{~h}$. This is a relatively short exposure from an industrial perspective but is long enough to reach breakaway oxidation on several alloys at both temperatures and to clearly reveal important trends and differences in alloy behavior.

\section{Experimental Procedures}

A number of commercial wrought high-temperature alloys were selected for investigation. Selection was made to represent available chromia as well as alumina-forming materials ranging from low to high levels of $\mathrm{Ni}$ and the presence of strengthening elements. Some alloys are optimized for use at substantially lower temperatures and special applications, and the results should be interpreted with this in mind. Materials were collected from commercial sources, and more information about the alloys is available on the homepages of the producers [4]. In order to make sure that conclusions are based on the actual compositions of the investigated sample, all alloys were analyzed using inductively coupled plasma optical emission spectrometry (ICP-OES) and matrix-matched calibration solutions, see Table 1. Several alloys contain reactive elements that are important for oxidation performance [1] and may be regarded as current commercially applied state of the art in 
Table 1 Measured chemical composition of the tested alloys

\begin{tabular}{|c|c|c|c|c|c|c|c|}
\hline Alloy & $\mathrm{Ni}$ & $\mathrm{Cr}$ & $\mathrm{Fe}$ & $\mathrm{Mn}$ & $\mathrm{Si}$ & Other & $\begin{array}{l}\text { Main } \\
\text { oxide }\end{array}$ \\
\hline Kanthal $^{\circledR}$ A1 & & 21 & Balance & & & $\mathrm{Al}$ (5.7), RE added & Alumina \\
\hline Kanthal ${ }^{\circledR} \mathrm{AF}$ & & 21 & Balance & & & $\mathrm{Al}$ (5.3), RE added & Alumina \\
\hline Kanthal APM ${ }^{\mathrm{TM}}$ & & 21 & Balance & & & $\mathrm{Al}$ (5.7), RE added & Alumina \\
\hline Kanthal $\mathrm{APMT}^{\mathrm{TM}}$ & & 21 & Balance & & & $\mathrm{Al}$ (5.0), RE added & Alumina \\
\hline PM 2000 & & 19 & Balance & & & $\mathrm{Al}$ (5.5), RE added & Alumina \\
\hline Nikrothal ${ }^{\circledR}$ PM 58 & Balance & 19 & 18 & & 0.4 & Al (5), RE added & Alumina \\
\hline $253 \mathrm{MA}^{\circledR}$ & 11 & 18 & Balance & 0.6 & 1.2 & $\mathrm{~N}(0.17), \mathrm{Ce}(0.05)$ & Chromia \\
\hline Alloy 316 & 12 & 14 & Balance & 1.5 & 0.5 & Mo (2.2) & Chromia \\
\hline Alloy 310 & 20 & 20 & Balance & 1.1 & 0.2 & Mo (0.39), Cu (0.20) & Chromia \\
\hline Incoloy ${ }^{\circledR} 800 \mathrm{H}$ & 29 & 19 & Balance & 0.7 & 0.3 & $\mathrm{Al}(0.25), \mathrm{Ti}(0.4)$ & Chromia \\
\hline $353 \mathrm{MA}^{\circledR}$ & 32 & 28 & Balance & 1.3 & 1.1 & $\mathrm{~N}(0.17), \mathrm{Ce}(0.04)$ & Chromia \\
\hline Incoloy ${ }^{\circledR}$ RA330 ${ }^{\circledR}$ & 33 & 19 & Balance & 1 & 1.0 & $\mathrm{Cu}(0.09)$ & Chromia \\
\hline Nikrothal $^{\circledR} 40$ & 34.5 & 20 & Balance & 0.55 & 2 & RE added & Chromia \\
\hline Nikrothal ${ }^{\circledR} 45 \mathrm{OC}$ & 45 & 21 & Balance & 0.40 & 1.5 & RE added & Chromia \\
\hline Hastelloy ${ }^{\circledR}$ C-276 & Balance & 18 & 6 & 0.4 & 0.2 & $\begin{array}{l}\text { Mo (16), W (3), Co (0.3), } \\
\text { V(0.01) }\end{array}$ & Chromia \\
\hline Nikrothal $^{\circledR} 60$ & 58 & 17 & Balance & 0.5 & 1.4 & RE added & Chromia \\
\hline Inconel $^{\circledR} 625$ & Balance & 22 & 4 & 0.2 & 0.4 & $\begin{array}{l}\mathrm{Mo}(10), \mathrm{Nb}(3.3), \mathrm{Al}(0.2) \\
\quad \mathrm{Ti}(0.2), \mathrm{Co}(0.9)\end{array}$ & Chromia \\
\hline Haynes $^{\circledR} 230^{\circledR}$ & Balance & 22 & 0.9 & 0.5 & 0.4 & $\begin{array}{l}\text { Mo (1.3), Al (0.4), W (14), } \\
\text { Co }(0.09)\end{array}$ & Chromia \\
\hline Inconel $^{\circledR} 601$ & Balance & 23 & 13 & 0.3 & 0.3 & $\mathrm{Al}(1.5), \mathrm{Cu}(0.22)$ & Chromia \\
\hline $\begin{array}{l}\text { Incoloy }^{\circledR} \\
\text { RA602CA }\end{array}$ & Balance & 25 & 9 & 0.04 & 0.04 & $\begin{array}{l}\mathrm{Al}(2.2), \mathrm{Ti}(0.15), \mathrm{Y}(0.1) \\
\mathrm{Zr}(0.1)\end{array}$ & (Alumina) \\
\hline Nikrothal $^{\circledR} 80$ & 78 & 20 & 1 & 0.25 & 1.4 & RE added & Chromia \\
\hline
\end{tabular}

this respect, but the details of these elements and their effects are not treated further here.

Material samples were cut from strip, plate or bar in delivery condition to nominal size approximately $10 \times 20 \times 2 \mathrm{~mm}$ and grinded with $\mathrm{SiC}$ paper to 500 mesh on all surfaces. Actual dimensions were measured, and the surface area was calculated. Before exposure, samples were degreased in alcohol in ultrasonic bath for $15 \mathrm{~min}$. Samples were placed in $>99.6 \%$ pure alumina crucibles that were degassed and stabilized by exposing them to 72 bake cycles of $1 \mathrm{~h}$ up to $1300{ }^{\circ} \mathrm{C}$ and checking for $<0.10 \mathrm{mg}$ weight change between exposures. Nevertheless, some negative numbers for spalling (actually crucible + possible spall) were achieved for the alumina formers which indicate a possibility of gross mass loss of samples or more likely crucibles during the exposure. The measured maximum mass losses are, however, small, $<0.08 \mathrm{mg} / \mathrm{cm}^{2}$, and is therefore $\leq 6 \%$ of the total final mass change in all cases.

It is known that temperature cycling in many applications accelerates the oxidation and consequently is a very important life-limiting factor. Exposure was 
therefore performed in air using 100-h cycles and cooled to room temperature between cycles. All crucibles were placed side by side on a tray made from Kanthal APMT. Heating was done by inserting the tray into a hot laboratory chamber furnace, and cooling was done by removing the tray with crucibles/samples and letting them cool naturally to room temperature. A lid made from Kanthal APMT plate was placed on top of the crucibles during cooling to prevent crosscontamination from flying spall particles during cool down when the absolute majority of spallation occur. However, even with this precaution, the small gap between the lid and the crucibles allowed a few oxide particles from nickelchromium alloys to be found in the crucibles with alumina formers after oxidation at $1200{ }^{\circ} \mathrm{C}$. Although the impact in terms of weight changes was negligible, at the subsequent $1100{ }^{\circ} \mathrm{C}$ exposure, each crucible was covered by a separate lid during cooling. Visual appearance, gross mass gain and amount of spallation were monitored after every 100-h cycle. The weighing procedure was as follows: weigh crucible including sample and then immediately only crucible with sample lifted. By deducting original crucible weight, this procedure gave a direct measurement of gross mass gain and spallation. Any volatiles leaving the samples as a gas phase were not collected and will be regarded as an unknown parameter in the following. It is known that gaseous $\mathrm{CrO}_{3}$ and $\mathrm{CrO}_{2}(\mathrm{OH})_{2}$ are formed in air at normal moisture levels on chromia formers [5] and this is an uncertain factor mainly in the gross mass gain numbers for the chromia formers, since already formed and spalled solid $\mathrm{Cr}_{2} \mathrm{O}_{3}$ may be assumed to be relatively stable toward further reaction.

Investigation of topography and cross sections was performed by visual inspection, digital camera, light optical microscope (LOM) and scanning electron microscope (SEM) with energy-dispersive X-ray spectroscopy (EDS) at breakaway or at $1000 \mathrm{~h}$ depending on what occurred first. In order to investigate the details of the earlier part of the oxidation process, separate samples from all materials were exposed in the same conditions for one single 100-h cycle and were then investigated in the same manor.

\section{Results and Discussion}

Alumina formers have a great advantage over chromia formers in terms of gross mass gain, spallation of oxide fragments and emission of volatiles, clearly exemplified in Fig. 1. The measured gross mass gain and spallation are shown in Fig. 2. All alumina formers and some chromia formers will have an oxidationlimited lifetime substantially longer than the 1000-h duration under the test conditions. This means that the differences in oxidation behavior between the alloys in terms of oxidation-limited lifetime are very large and exceed more than an order of magnitude [3]. In order to compare corrosion mechanisms, cross sections of all alloys were studied on the 100-h exposed samples at both temperatures. Greatly, varying level of attack is evident from polished sections investigated in SEM as shown in Fig. 3, all at the same magnification. Alloy 316 is excluded from the diagram due to excessive oxidation. 
(a)
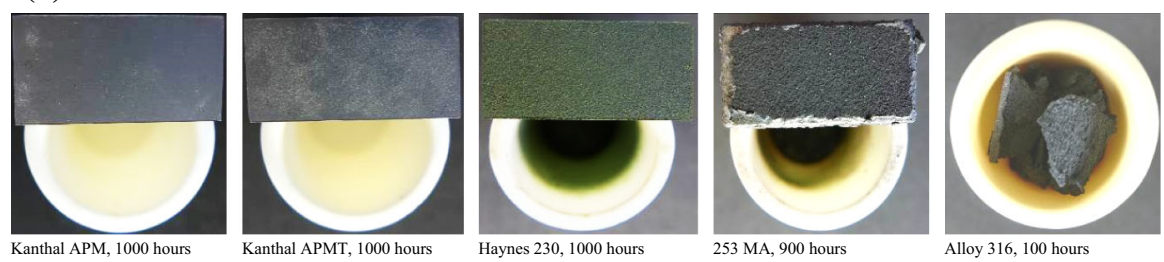

(b)
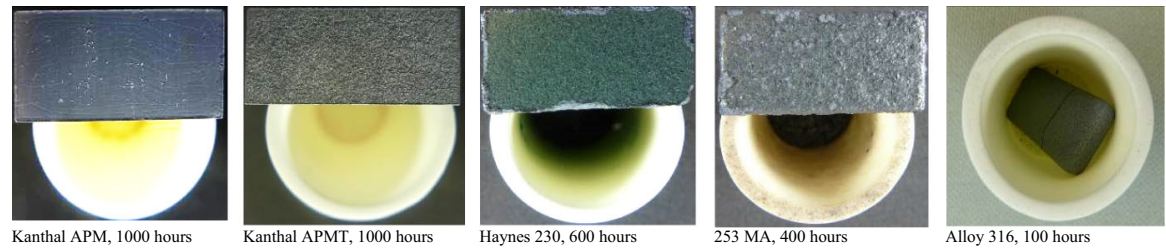

Fig. 1 Some examples of visual appearance of sample (resting on the rim of its crucible for the photo) and crucible after breakaway or $1000 \mathrm{~h}$. Note the discoloration of the alumina crucible extending up to approximately the height of the sample on Haynes 230. A similar discoloration is shown by all chromia formers. a $1100{ }^{\circ} \mathrm{C}$, b $1200{ }^{\circ} \mathrm{C}$

The alumina formers typically show sub-parabolic oxidation kinetics both at $1100{ }^{\circ} \mathrm{C}$ and at $1200{ }^{\circ} \mathrm{C}$ with exponents ranging from about 0.3 to 0.4 . At both temperatures, the austenitic alumina former Nikrothal 58PM shows a somewhat higher exponent, 0.46 at $1100{ }^{\circ} \mathrm{C}$ and 0.62 at $1200{ }^{\circ} \mathrm{C}$, and a somewhat larger spallation than the ferritic alumina formers. Compared to chromia formers, the spallation is nevertheless very small.

The chromia formers show a much larger spread in oxidation performance. The best alloys show relatively small spallation and are close to parabolic oxidation kinetics. Looking at the outcome in gross oxidation behavior, some features can be distinguished that are important for the oxidation behavior. Ability to form partial $\mathrm{Si}$ and Al-rich scales, formation of voids and spallation are characteristic features and are therefore discussed below in some detail.

\section{Ability to Form Silica- and Aluminum-Rich Oxides in Ni-Base Alloys}

Alloys may have similar levels of $\mathrm{Ni}$ and $\mathrm{Cr}$, but still show a large difference in oxidation behavior. A high $\mathrm{Ni}$ content is generally a positive factor, but there are large deviations from this rule. A good illustration is alloy 316 that behaves the worst and does not survive even $100 \mathrm{~h}$ at $1100{ }^{\circ} \mathrm{C}$, whereas an alloy with similar $\mathrm{Ni}$ content, 253MA, survives about $900 \mathrm{~h}$, which in turn is better than several alloys with $30-40 \% \mathrm{Ni}$ that show breakaway oxidation before this time. The ability to form silica- and/or alumina-rich layers plays a key role as is evident from the microstructures and the mass gains. Beneath a Cr-rich outer oxide, a more or less discontinuous layer of silica is apparent on the alloys with better kinetics, and there is a strong correlation between the degree of silica coverage and oxidation performance. Even at Si levels as low as $0.3 \mathrm{wt} \%$ as the case in alloy $800 \mathrm{H}$, some 

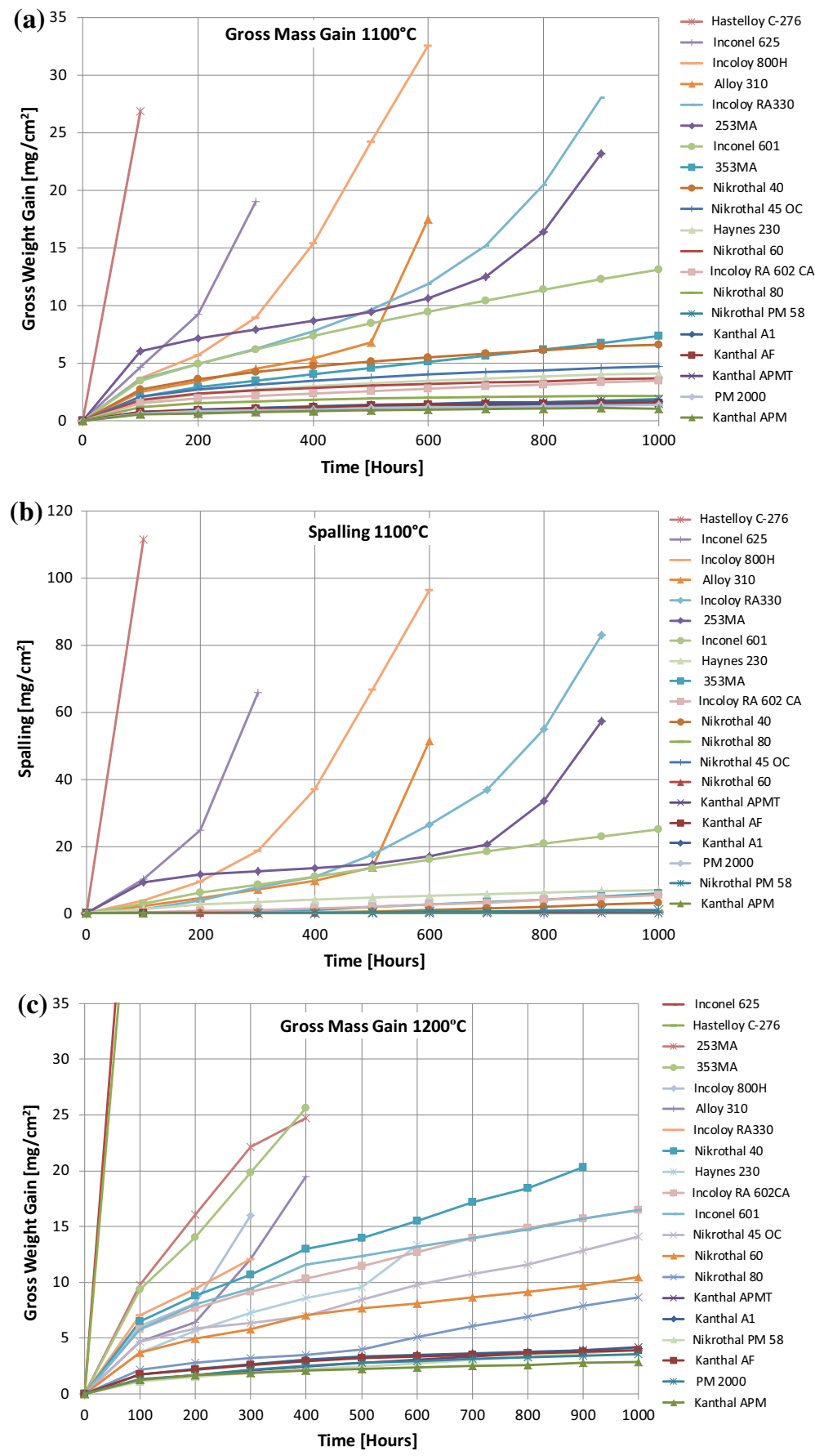

Fig. 2 Gross mass gain and spallation. The designations are arranged from high to low in each diagram in order to facilitate interpretation. a Gross $1100{ }^{\circ} \mathrm{C}$, b Spall $1100{ }^{\circ} \mathrm{C}$, c Gross $1200{ }^{\circ} \mathrm{C}$, d Spall $1200{ }^{\circ} \mathrm{C}$ 


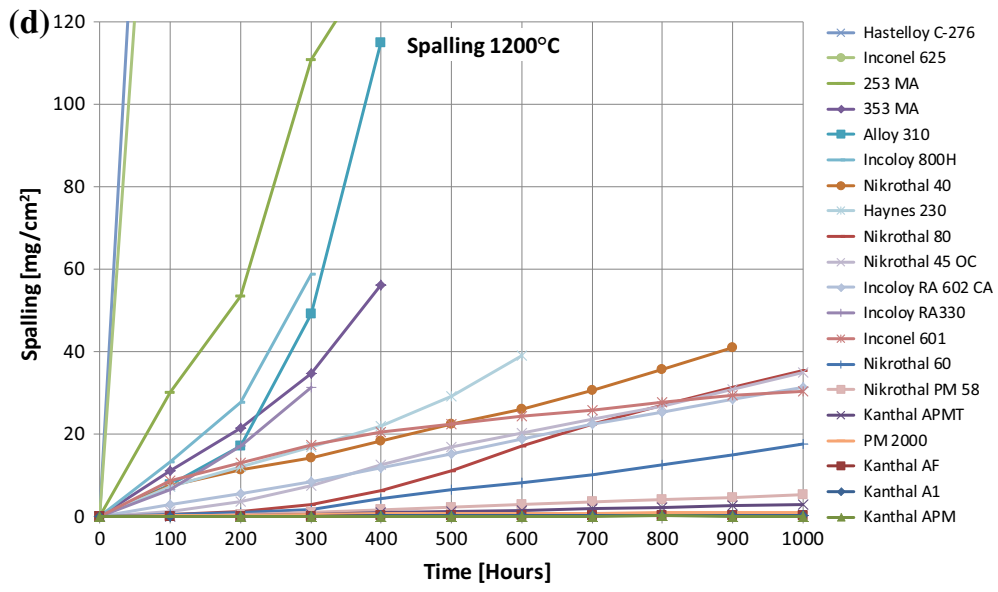

Fig. 2 continued

silica is present beneath the chromia scale, although this is much more pronounced in alloys as Nikrothal $45 \mathrm{OC}$ with a level of $1.5 \mathrm{wt} \% \mathrm{Si}$. It seems that the shape and penetration of the formed silica has a correlation to Ni content, where a high level of $\mathrm{Ni}$ (or lower level of $\mathrm{Fe}$ ) gives a more beneficial protection.

Several chromia formers contain some levels of Al, and Al-rich oxides beneath an external chromia scale are evident in some of the alloys with better kinetics. Chemical stability of $\mathrm{Al}_{2} \mathrm{O}_{3}$ is high enough to be stable even below outer scales of chromia and silica. The morphology of the formed alumina varies greatly with $\mathrm{Al}$ content between continuous and semi-continuous layers at high Al levels to small scattered inclusions at background Al levels. Among the tested alloys, there is a range in $\mathrm{Al}$ content from about $5 \mathrm{wt} \%$ down to background levels. The oxidation behavior in terms of $\mathrm{Al}$ and $\mathrm{Si}$ level may be grouped in four main categories or alloy design strategies.

I. External alumina scale at both temperatures

II. Hybrid alumina and chromia scale

III. External chromia scale with internal alumina formation

IV. External chromia with internal semi-continuous silica

Some of the alloys illustrate the behaviors in Fig. 4. It can be concluded that strategy I followed by IV in combination with a high content of $\mathrm{Ni}$ are effective strategies at $1200{ }^{\circ} \mathrm{C}$, whereas I, II and IV (even at lower Ni content) can give low oxidation rates at $1100{ }^{\circ} \mathrm{C}$. Strategy III as exemplified by alloy 601 gives faster kinetics as compared to some other alloys with similar $\mathrm{Ni}$ content at $1100{ }^{\circ} \mathrm{C}$ but works somewhat better at $1200{ }^{\circ} \mathrm{C}$. 
(a)

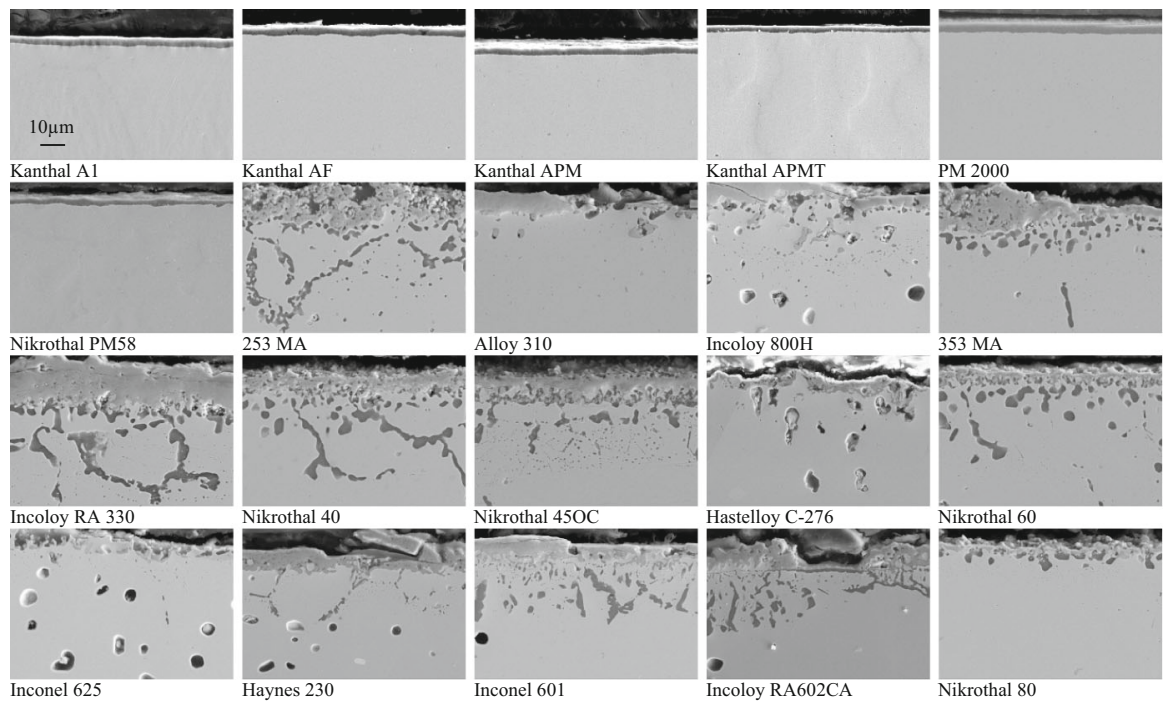

(b)
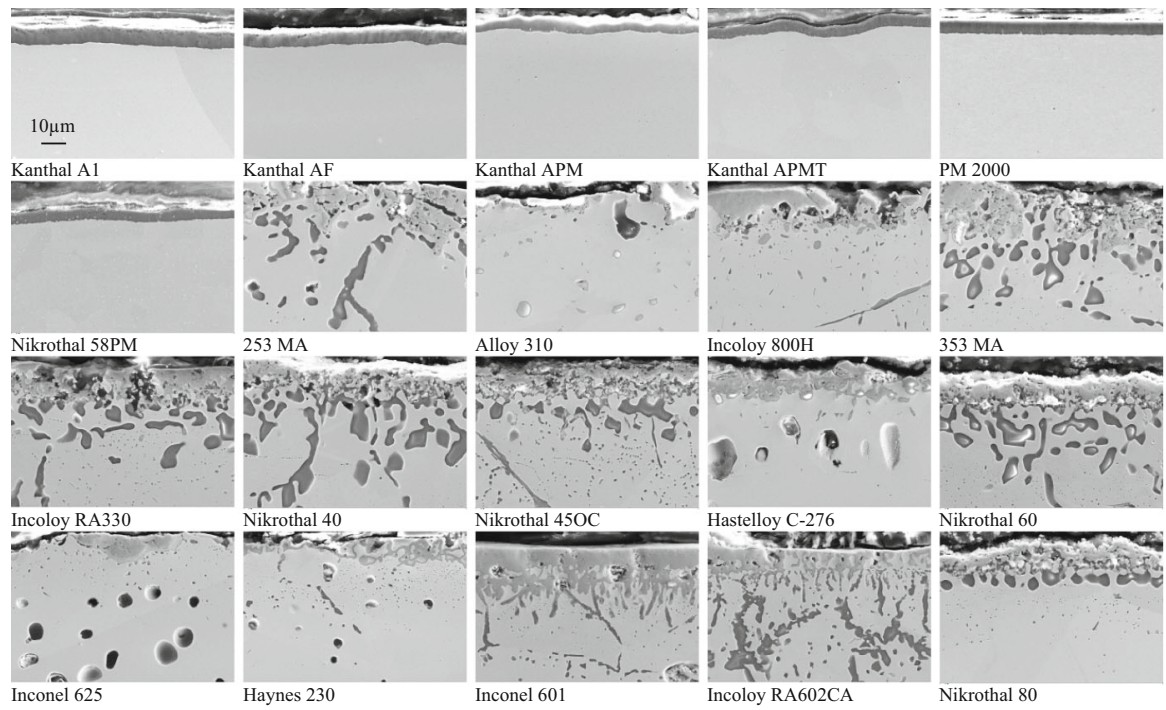
PM 2000

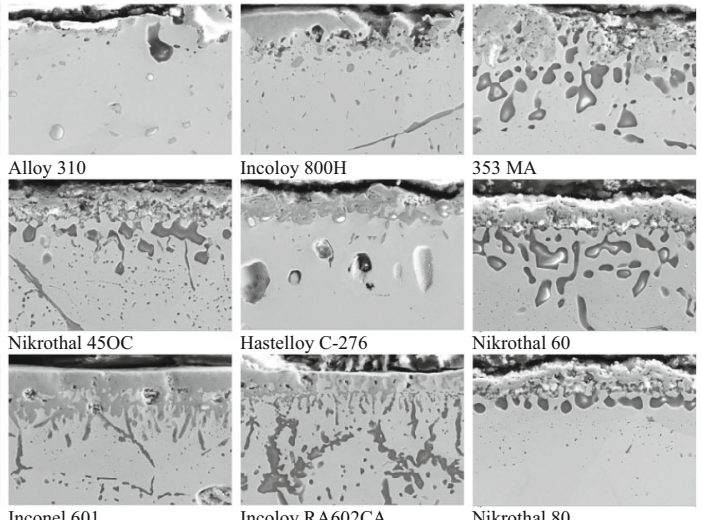

Inconel 601

Incoloy RA602CA

Nikrothal 80

Fig. 3 Cross sections after 100 -h exposure, SEM a $1100{ }^{\circ} \mathrm{C}$, b $1200{ }^{\circ} \mathrm{C}$

\section{Presence of Voids}

Internal voids were formed in several of the chromia-forming alloys, and the number and size relate to amount of gross mass gain. For example, Inconel 601, as a consequence to its relatively fast kinetics, exhibits massive amounts of voids after 1000-h exposure and therefore illustrates the behavior, see Fig. 5. Oxidation at the surface involves consumption of $\mathrm{Cr}$ in chromia formers by outward diffusion of 


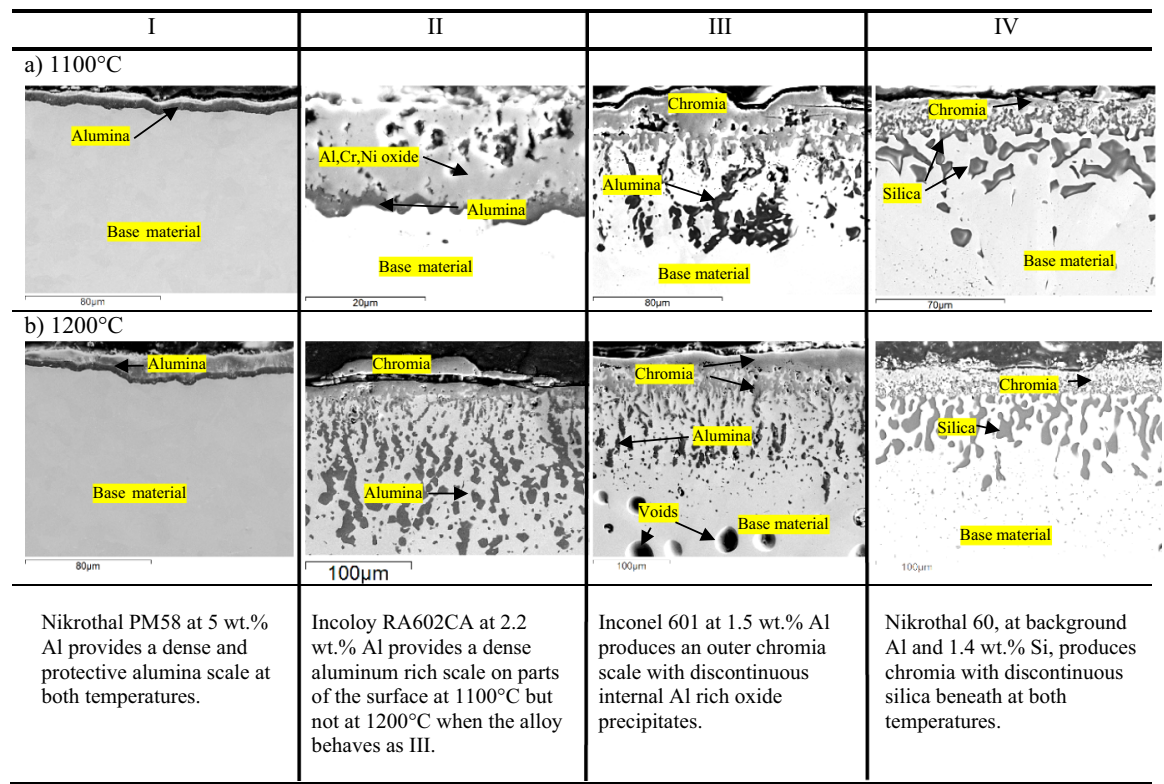

Fig. 4 Representative examples of polished sections investigated in SEM and EDS after $1000 \mathrm{~h}$ grouped in main categories. Point analysis highlights $\mathrm{Cr}-, \mathrm{Si}$ - and Al-rich oxides as labeled. a $1100{ }^{\circ} \mathrm{C}, \mathbf{b} 1200{ }^{\circ} \mathrm{C}$

(a)

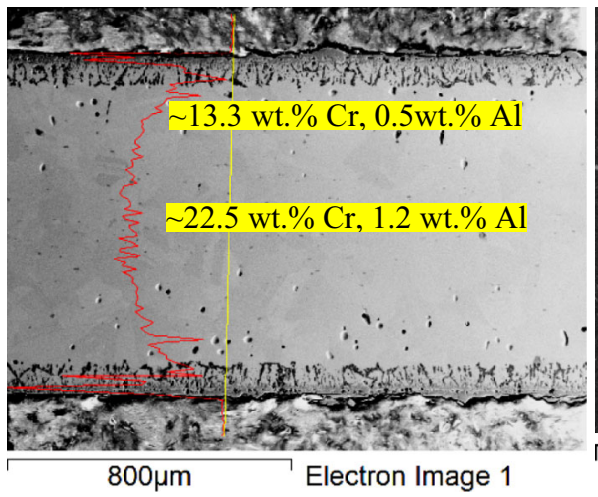

(b)

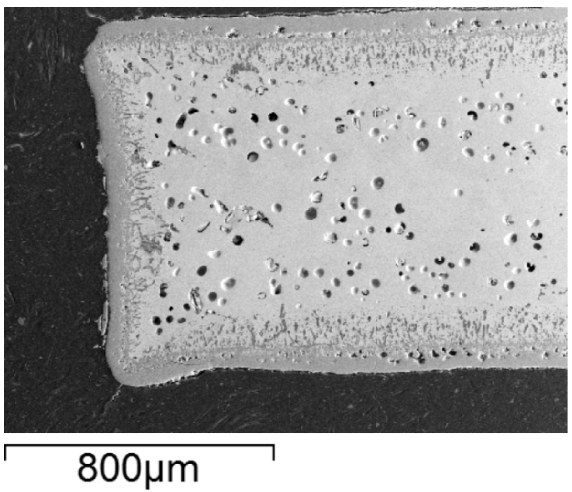

Fig. 5 Inconel 601 oxidized for $1000 \mathrm{~h}$. Polished cross sections. a SEM and EDS-Cr line scan and measured $\mathrm{Al}$ at $1100{ }^{\circ} \mathrm{C}$, b SEM $1200{ }^{\circ} \mathrm{C}$

metal cations and inward diffusion of oxygen and/or vacancies; this can give rise to pores primarily in the scale metal interface. Some pores are located in this area, but the majority of the pores are distributed further into the metal, and therefore another mechanism seems more important. The $\mathrm{Cr}$ depletion close to the surface is $\sim 10 \mathrm{wt} \%$. Alloy 601 contains nominally $1.5 \mathrm{wt} \% \mathrm{Al}$, and also $\mathrm{Al}$ shows depletion as seen in Fig. 5a. The oxidation process therefore involves large flux of $\mathrm{Cr}$ and $\mathrm{Al}$ toward the surface. The counter flux of $\mathrm{Ni}$ and $\mathrm{Fe}$ is not fast enough, and the 
mismatch therefore results in an unbalanced mass flow and pore formation, often referred to as Kirkendall porosity. Note also the slight cushion shape that results from a macroscopic shrinking of the core. Recently, the phenomena have been treated quantitatively by Desrange et al. [6].

\section{Amount of Spallation}

Spalling is a negative factor for the users of high-temperature components since it affects the environment surrounding the surface, e.g., in industrial heat treatment processes. Spalled oxide contaminates the heated goods, creates shortcuts in heating elements and clogs gas passages, etc. It also correlates to amount of oxidation since each spall event results in a thinner protective scale and therefore a larger rate of gross oxidation. The spallation of chromia formers is in general much larger than that of alumina formers but there are very large variations within the group. A way to visualize the importance of spallation is to look at the actual amount of spallation in relation to the total oxidation. This may be expressed as

$$
\text { Spall } \text { contribution }=\frac{\text { Oxygen in spall }}{\text { Gross }}=\frac{\text { Spall } \times f}{\text { Gross }}
$$

where the factor $f$ is the oxygen content of the spalled oxide. Since only a fraction of the oxide is oxygen, the weight of the spallation may actually be larger than the total oxidation (gross weight gain) and this is in fact often the case for chromia formers. Assuming pure alumina on alumina formers and pure chromia on chromia formers, $f$ is taken as 0.47 and 0.32 , respectively. In reality this is not really true, since chemical analysis of the spalled material gave as a result that it contains at least a few wt $\% \mathrm{Ni}$ and $\mathrm{Fe}$ in a range from less than 1 up to more than $50 \mathrm{wt} \%$ on the $\mathrm{Fe}$ base 253MA (after breakaway) oxidation.

The result on spall contribution to the total oxidation versus time based on the measured values and this assumption is shown in Fig. 6a. As seen from the diagram, the ratio is large for many alloys and it also increase with time for several alloys. Very large values may indicate that the spalled material actually contains not only chromia or alumina, but also lower oxides or spinel. A simple check revealed that the spallation on several alloys is partially magnetic which supports this indication and $f$ would then be overestimated.

Another reason for high values would be if the sample lost substantial weight due to evaporation since that would underestimate gross gain. It was, however, observed that the crucibles were discolored, supposedly from compounds transported as vapor, mainly up to the level of the height of the sample, see, e.g., Fig. 1 for Haynes 230. This indicates that most of the vaporized material actually was picked up within the crucible and therefore was accounted for in the measurements. Even with these possible sources of error in mind, the result clearly illustrates that crosssectional analysis and measurement of depth of attack alone on exposed components will underestimate the magnitude of attack since a majority of the corrosion products may have left the sample in the form of spallation or vapor.

As expected, there is a correlation between amount of spallation and oxidation performance within the group of chromia formers that is shown in Fig. 6b. The 

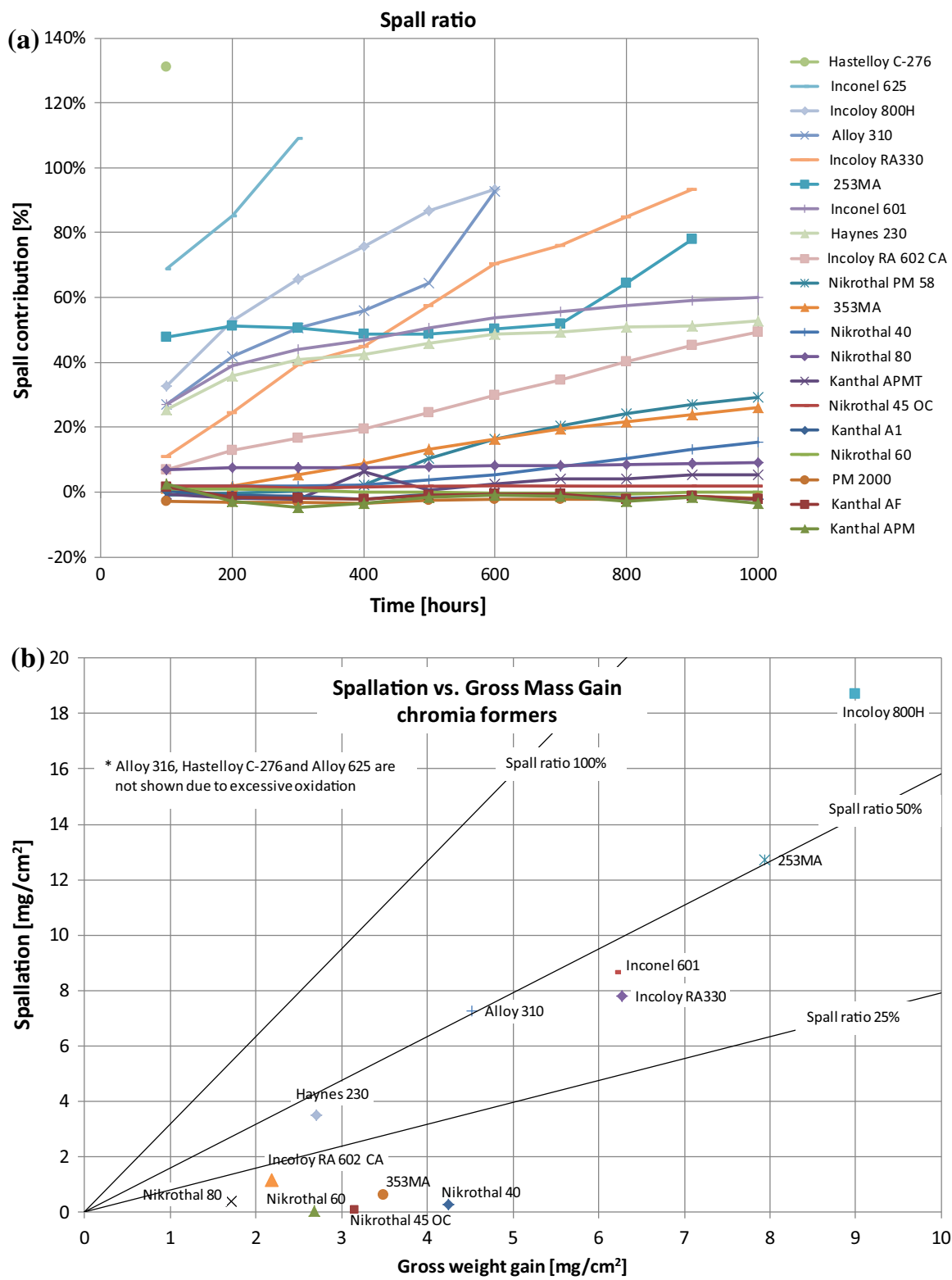

Fig. 6 a Contribution of spall to total oxidation at $1100{ }^{\circ} \mathrm{C}$, assuming that all spalled oxide is alumina and chromia for alumina and chromia formers, respectively. $\mathbf{b}$ Relation between amount of spall and total oxidation (gross mass gain) for chromia formers after $300 \mathrm{~h}$ at $1100{ }^{\circ} \mathrm{C}$

chromia formers are split in two categories, with high and low spallation, respectively. Note that the comparison was done after one specific time, $300 \mathrm{~h}$, in order to have most alloys still in the test. Alloy 316, Hastelloy C-276 and Alloy 625 are not shown due to excessive oxidation. 


\section{Conclusions}

At both tested temperatures, 1100 and $1200{ }^{\circ} \mathrm{C}$, the gross mass gains as well as amount of spallation and emittance of volatiles show that alumina formation gives by far the best protection and this holds true for the tested ferritic as well as austenitic alloys.

Some chromia-forming alloys nevertheless show protective oxidation even at $1200{ }^{\circ} \mathrm{C}$, but there are extremely large variations within the group. Morphology of the scales as well as chemical analysis of the oxidation zone shows as expected that high $\mathrm{Ni}$ content generally is a positive factor, but also that Si and Al play a very important role in terms of gross oxidation and spallation that in several cases overrides the impact of $\mathrm{Ni}$ content. At $1200{ }^{\circ} \mathrm{C}$, alloys with high $\mathrm{Ni}$ content and $\mathrm{Si}$ additions show relatively protective behavior but most chromia-forming alloys suffer from relatively rapid oxidation, extensive spallation and emission of chromium-containing volatiles.

Open Access This article is distributed under the terms of the Creative Commons Attribution 4.0 International License (http://creativecommons.org/licenses/by/4.0/), which permits unrestricted use, distribution, and reproduction in any medium, provided you give appropriate credit to the original author(s) and the source, provide a link to the Creative Commons license, and indicate if changes were made.

\section{References}

1. D. Young, High Temperature Oxidation and Corrosion of Metals, (Elsevier, 2008). ISBN: 978-0-08044587-8.

2. M. Glaser, Industrial Heating September, 59-65 (2014).

3. B. Jönsson, et al., Oxidation of Metals 79, 29-39 (2013).

4. Web sites, www.kanthal.com, www.haynesintl.com, www.specialmetals.com, www.rolledalloys.com

5. H. Asteman, J. E. Svensson and L. G. Johansson, Oxidation of Metals 57, 193 (2002).

6. C. Desranges, et al., Oxidation of Metals 79, 93-105 (2013). 